\title{
Culture temperature affects redifferentiation and cartilaginous extracellular matrix formation in dedifferentiated human chondrocytes.
}

\section{AUTHOR(S):}

Ito, Akira; Aoyama, Tomoki; lijima, Hirotaka; Tajino, Junichi; Nagai, Momoko; Yamaguchi, Shoki; Zhang, Xiangkai; Kuroki, Hiroshi

\section{CITATION:}

Ito, Akira ... [et al]. Culture temperature affects redifferentiation and cartilaginous extracellular matrix formation in dedifferentiated human chondrocytes.. Journal of orthopaedic research 2015, 33(5): 633-639

\section{ISSUE DATE:}

2015-03-05

\section{URL:}

http://hdl.handle.net/2433/200682

\section{RIGHT:}

This is the peer reviewed version of the following article: Ito, A., Aoyama, T., lijima, H., Tajino, J., Nagai, M., Yamaguchi, S., Zhang, X. and Kuroki, H. (2015), Culture temperature affects redifferentiation and cartilaginous extracellular matrix formation in dedifferentiated human chondrocytes. J. Orthop. Res., 33: 633-639, which has been published in final form at http://dx.doi.org/10.1002/jor.22808. This article may be used for non-commercial purposes in accordance with Wiley Terms and Conditions for Self-Archiving.; The full-text file will be made open to the public on 5 MAR 2016 in accordance with publisher's 'Terms and Conditions for Self-Archiving'; この論文は出版社版でありません。引用の際には出版社版 をご確認ご利用ください。; This is not the published version. Please cite only the published version. 
Journal Orthopaedic Research 2015 May;33(5):633-9. doi: 10.1002/jor.22808.

1 Culture temperature affects redifferentiation and cartilaginous extracellular matrix

2 formation in dedifferentiated human chondrocytes

3

4 Akira Ito ${ }^{1,2}$, Tomoki Aoyama ${ }^{3}$, Hirotaka Iijima ${ }^{1}$, Junichi Tajino ${ }^{1}$, Momoko Nagai ${ }^{1}$, Shoki

$5 \quad$ Yamaguchi $^{1,2}$, Xiangkai Zhang $^{1}$, Hiroshi Kuroki ${ }^{1 *}$

$6{ }^{1}$ Department of Motor Function Analysis, Human Health Sciences, Graduate School of

7 Medicine, Kyoto University, Kyoto, Japan

$8 \quad{ }^{2}$ Japan Society for the Promotion of Science, Tokyo, Japan

$9{ }^{3}$ Department of Development and Rehabilitation of Motor Function, Human Health Sciences,

10 Graduate School of Medicine, Kyoto University, Kyoto, Japan

11

$12 *$ Corresponding author:

13 Hiroshi Kuroki

1453 Kawahara-cho, Shogoin, Sakyo-ku, Kyoto 606-8507, Japan

15 Tel: +81-75-751-3963; Fax: +81-75-751-3909

16 E-mail: kuroki.hiroshi.6s@kyoto-u.ac.jp

17

Running title: Culture temperature in chondrocytes 
Abstract

21 To date, there have been few studies on how temperature affects the phenotype and

22 metabolism of human chondrocytes. Thus, the purpose of this study was to elucidate the

23 effects of culture temperature on chondrocyte redifferentiation and extracellular matrix

24 (ECM) formation using dedifferentiated mature human chondrocytes in vitro.

25 Dedifferentiated chondrocytes were cultured in a pellet culture system for up to 21 days. The

26 pellets were randomly divided into three groups with different culture temperature $\left(32^{\circ} \mathrm{C}\right.$,

$2737^{\circ} \mathrm{C}$, and $41^{\circ} \mathrm{C}$ ). Chondrocyte redifferentiation and ECM formation were evaluated by wet weight, messenger ribonucleic acid (mRNA), histological, and biochemical analyses. The results showed that the wet weight and the mRNA expressions of collagen type II A1 and cartilage oligomeric matrix protein at $37^{\circ} \mathrm{C}$ were higher than the corresponding values at $32^{\circ} \mathrm{C}$. The histological and biochemical analyses revealed that the syntheses of type II collagen and proteoglycan were promoted at $37^{\circ} \mathrm{C}$ compared to those at $32^{\circ} \mathrm{C}$, whereas they were considerably inhibited at $41^{\circ} \mathrm{C}$. In conclusion, the results obtained herein indicated that temperature affects chondrocyte redifferentiation and ECM formation, and modulation of temperature might thus represent an advantageous means to regulate the phenotype and biosynthetic activity of chondrocytes.

Keywords: chondrocyte; temperature; extracellular matrix; differentiation; pellet culture. 
Articular cartilage (AC) is a hyaline cartilage composed of a dense cartilaginous extracellular matrix (ECM) with sparse distribution of highly specialized cells called chondrocytes. Recently, tissue engineering and cell-based therapies have been explored for AC regeneration, ${ }^{1}$ since AC displays a limited capacity for renewal and self-repair. ${ }^{2}$ Autologous chondrocyte implantation (ACI) is a promising cell-based therapy for repairing AC defects. ${ }^{3}$ However, ACI poses several challenges. Harvested chondrocytes must be expanded to obtain a large number of cells for transplantation, and yet, this process results in the induction of chondrogenic phenotype loss (i.e., dedifferentiation), ${ }^{4,5}$ causing fibro-cartilage-like remodeling. Thus, characterization of the factors regulating the chondrogenic phenotype is desired for inducing redifferentiation and hyaline cartilage for ECM formation. Candidate factors include the microenvironment, such as the presence of growth factors, ${ }^{6}$ scaffolds, ${ }^{7}$ and oxygen tension, ${ }^{8}$ as well as mechanical stimuli. ${ }^{9}$ While these factors have all been well studied, there are conversely few studies that have focused on the role of temperature in chondrocyte redifferentiation. ${ }^{10}$ Environmental temperature is known to influence some tissues such as the skin. Interestingly, the temperature within the human knee joint is also influenced by the environmental temperature, with a mean temperature of approximately $32^{\circ} \mathrm{C}$, which is $4-5^{\circ} \mathrm{C}$ lower than the inner body temperature. ${ }^{11,12}$ However, most in vitro studies on chondrocytes or AC have been performed using a culture temperature of $37^{\circ} \mathrm{C}$, which may not accurately reflect the in vivo temperature. In addition, the effect of a high-temperature environment, such as $41^{\circ} \mathrm{C}$, remains unclear, although an intermittent heat stimulus $\left(41^{\circ} \mathrm{C}\right)$ has been reported to potentially have a positive effect on ECM formation. ${ }^{13,14}$

To date, there are few studies on how temperature affects the chondrocyte phenotype and metabolism of mature human chondrocytes. We hypothesized that the culture temperature 
may influence the ability of dedifferentiated chondrocytes to redifferentiate and produce hyaline-like ECM. Therefore, the purpose of this study was to elucidate the effects of culture temperature (from physiological- to high-temperature) on redifferentiation and ECM formation using dedifferentiated mature human chondrocytes in vitro.

Methods

\section{Chondrocyte isolation and pellet culture}

Human chondrocytes were obtained from the femoral heads (International Cartilage Repair Society grade 0) extracted during bipolar hip arthroplasty performed in two 62- and 89-year-old women (donors A and B, respectively), as previously described. ${ }^{15}$ The Ethics Committee of the Faculty of Medicine at Kyoto University approved the procedure, and informed consent was obtained from the donors. The isolated cells from the donors were separately expanded in Dulbecco's modified Eagle medium/Ham's F12 (Nacalai Tesque Inc., Kyoto, Japan) containing 10\% fetal bovine serum (Hyclone, Logan, UT), $50 \mathrm{U} / \mathrm{mL}$ penicillin (Nacalai Tesque Inc.), and $50 \mu \mathrm{g} / \mathrm{mL}$ streptomycin (Nacalai Tesque Inc.) to dedifferentiate in tissue culture dishes in a $\mathrm{CO}_{2}$ incubator $\left(5 \% \mathrm{CO}_{2}\right.$ at $37^{\circ} \mathrm{C}$ with $95 \%$ humidity) until passage two or three.

To provide a 3-dimensional environment, a pellet culture system was used. ${ }^{16}$ The expanded chondrocytes were trypsinized and subsequently resuspended in a chondrogenic medium (Chondrogenic Differentiation Media BulletKit; Lonza, Walkersville, MD), which was supplemented with $10 \mathrm{ng} / \mathrm{mL}$ recombinant human transforming growth factor-beta 3 (R\&D Systems, Inc., Minneapolis, MN). Aliquots of $2.5 \times 10^{5}$ cells in $500 \mu \mathrm{L}$ of the chondrogenic medium were centrifuged at $250 \times g$ for $5 \mathrm{~min}$ in $15-\mathrm{mL}$ polypropylene conical tubes. The pelleted cells were randomly divided into three groups with different incubation 
temperatures $\left(32^{\circ} \mathrm{C}, 37^{\circ} \mathrm{C}\right.$, and $\left.41^{\circ} \mathrm{C}\right)$. These temperatures were defined as follows: $32^{\circ} \mathrm{C}$, physiological intra-articular temperature; $37^{\circ} \mathrm{C}$, conventionally used inner body temperature; and $41^{\circ} \mathrm{C}$, the threshold temperature for mammalian cell survival. ${ }^{17,18}$ The pellets from donor A were harvested at 3, 7, 14, and 21 days for analysis. The pellets from donor B cultured at $32^{\circ} \mathrm{C}$ and $37^{\circ} \mathrm{C}$ were harvested at 3 and 21 days to confirm the reproducibility of the findings from donor A. Throughout the study, " $n$ " indicates the technical replicates of the pellet cultures.

\section{Quantitative real-time reverse transcription-polymerase chain reaction (qRT-PCR)}

The generated pellets ( $n=3$ pellets/group) were harvested after 3 and 7 days. The total RNA was extracted and qRT-PCR was performed as previously described. ${ }^{15}$ The target genes and reference genes used were as follows: chondrogenesis markers (collagen type II A1 $[C O L 2 A 1]$, aggrecan $[A C A N]$, and cartilage oligomeric matrix protein $[C O M P]) ;$ a fibro-cartilage maker (collagen type I A1 [COL1A1]); and reference genes (ribosomal protein L13a $[R P L 13 a]$ and tyrosine 3-monooxygenase/tryptophan 5-monooxygenase activation protein $[Y W H A Z])$. Their specific primers are listed in Supplementary Table 1.

The data obtained by qRT-PCR were analyzed using the comparative threshold cycle method. Briefly, the quantity of the target genes was normalized to the expression levels of RPL13a and YWHAZ, which have been proven to be stable under different thermal conditions. ${ }^{19}$ The value of the calibration sample (cells cultured at $32^{\circ} \mathrm{C}$ on day 3 ) was set to 1 , and the values for the other conditions were reported relative to that of the calibration sample.

\section{Histological and immunohistochemical (IHC) analyses}


The generated pellets cultured in the three different temperatures obtained on days 7,14 ,

113 and 21 were stained with safranin-O/fast green for assessment of proteoglycan deposition, and with picrosirius red to visualize the collagen orientation and integrity under a polarizing

115 microscope (Eclipse 80i; Nikon, Tokyo, Japan). ${ }^{20}$ IHC staining of type II and I collagen was

116 performed to detect each type of collagen deposition according to previously described 117 methods. ${ }^{21}$ To semi-quantify the immunoreactivity of type II collagen at $32^{\circ} \mathrm{C}$ and $37^{\circ} \mathrm{C}$ on

118 day 21 , the images from each group ( $n=8$ pellets/group) were measured using the Image J program (National Institutes of Health, Bethesda, MD) as previously described. ${ }^{14}$

\section{Scanning electron microscope (SEM) observation}

SEM observation was performed to assess the ultra-microstructure of collagen fibers using a SEM system (H-7650; Hitachi, Tokyo, Japan). The generated pellets on day 21 were fixed and cut into two pieces. The specimen was mounted cut surface up on aluminum stubs. The collagen fibers on the surface, superficial, sub-superficial, transition, and deep regions on the cut surface of the pellets were observed.

\section{Measurement of glycosaminoglycan (GAG) and deoxyribonucleic acid (DNA) content}

The total GAG content in the pellets on days 14 and $21(n=6$ pellets/group) was content in these samples ( $n=6$ pellets/group) was assessed using the Quant-iT ${ }^{\mathrm{TM}}$ PicoGreen ${ }^{\circledR}$ assay (Invitrogen Ltd., Paisley, UK) following the manufacturer's instructions. content/pellet $\div$ DNA content/pellet). 
136

137

138

139

140

141

\section{Statistical analysis}

JMP 11 software (SAS Institute, Cary, NC) was used for the statistical analyses. Descriptive statistics were calculated as means and 95\% confidence intervals. Statistical significance for the donor A experiments was determined using the paired $t$-test for the semi-quantitative evaluation of type II collagen, or by one-way analysis of variance using the post-hoc multiple comparison Tukey-Kramer test for other experiments. For donor B, statistical significance was determined using the paired $t$-test. The correlation between GAG content and wet weight was examined using Pearson's correlation coefficient. The differences observed were considered to be significant if the $P$ value was $<0.05$.

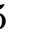

Results

The results from donors A and B showed similar trends. Therefore, only the results from donor $\mathrm{A}$ are described below, whereas the results from donor $\mathrm{B}$, which were used to confirm the reproducibility of the findings from donor A, are described in Supplementary Fig. 1.

\section{Wet weight measuring}

Representative pellets generated at the three different temperatures are shown in Fig. 1(a). The pellets generated at $32^{\circ} \mathrm{C}$ and $37^{\circ} \mathrm{C}$ showed a ball-like shape, whereas that at $41^{\circ} \mathrm{C}$ showed a disc-like shape. Fig. 1(b) shows the wet weight changes over time. Although the wet weight was heavier at $32^{\circ} \mathrm{C}$ than at the other temperatures on day 3 , the heaviest pellets were those cultured in $37^{\circ} \mathrm{C}$ obtained on days 14 and 21 . On the other hand, at $41^{\circ} \mathrm{C}$, the wet weight was significantly lighter than at the other temperature, and did not change over time.

\section{Gene expression analysis}


Gene expression analysis related to the cartilaginous ECM was performed on days 3 and

7 to analyze the early effects of temperature (Fig. 2). The gene expressions analyzed were found to be significantly down-regulated at $41^{\circ} \mathrm{C}$. Conversely, the expressions of $C O L 2 A 1$, COLIA1, ACAN, and COMP were all up-regulated on day 7 compared to those on day 3 at $32^{\circ} \mathrm{C}$ and $37^{\circ} \mathrm{C}$. The expressions of $C O L 2 A 1$ and $C O M P$ were significantly more up-regulated at $37^{\circ} \mathrm{C}$ than at $32^{\circ} \mathrm{C}$ on days 3 and 7 , whereas no significant differences were observed for the expressions of COL1A1 and ACAN in this early phase.

\section{Histological and IHC analyses}

Representative images are shown in Fig. 3. Safranin-O staining, type II collagen IHC staining, and picrosirius red staining revealed a progressive deposition at $32^{\circ} \mathrm{C}$ and $37^{\circ} \mathrm{C}$, but not at $41^{\circ} \mathrm{C}$. IHC staining of type I collagen showed early and intense deposition at $32^{\circ} \mathrm{C}$ and $37^{\circ} \mathrm{C}$, but not at $41^{\circ} \mathrm{C}$. Picrosirius red staining at $32^{\circ} \mathrm{C}$ was observed not only in the superficial region but also in the deep region (Fig. 3 [white arrow]) on days 14 and 21, while that at $37^{\circ} \mathrm{C}$ was observed mainly in the superficial region. To clarify the differences in type II collagen deposition between $32^{\circ} \mathrm{C}$ and $37^{\circ} \mathrm{C}$ on day 21 , semi-quantitative evaluation was performed. The mean intensity per pixel (Fig. 4a) and mean percentage of type II collagen positive area (Fig. 4b) were found to be significantly higher at $37^{\circ} \mathrm{C}$ than at $32^{\circ} \mathrm{C}$.

\section{SEM observation}

Fig. 5 shows representative images of the surfaces and cut surfaces of the pellets on day characteristics were not observed at $41^{\circ} \mathrm{C}$. In the superficial region, dense and layered collagen fiber formations parallel to the surface were observed at $32^{\circ} \mathrm{C}$ and $37^{\circ} \mathrm{C}$, whereas no 
184

185

collagen formations were observed at $41^{\circ} \mathrm{C}$. In the sub-superficial region, the collagen fibers were randomly oriented, and they appeared sparse through the deep region. The collagen fibers in the transition and deep regions at $32^{\circ} \mathrm{C}$ appeared denser than at $37^{\circ} \mathrm{C}$.

\section{Measurement of GAG and DNA content}

The GAG content per pellet at $41{ }^{\circ} \mathrm{C}$ was significantly lower than that at the other temperature environments (Fig. 6a). The GAG content in the pellet generated at $37^{\circ} \mathrm{C}$ tended to be higher than that obtained at $32^{\circ} \mathrm{C}$. Moreover, the DNA content per pellet at $41^{\circ} \mathrm{C}$ was significantly lower than that at the other temperature environments (Fig. 6b). When the GAG content was normalized according to the DNA content, the value was found to be significantly higher at $37^{\circ} \mathrm{C}$ compared to at $32^{\circ} \mathrm{C}$ on day 21 (Fig. 6c). The GAG content and the wet weight had a strong positive correlation $\left(R^{2}=0.91, P<0.01, n=36\right)$ (Supplementary Fig. 2).

\section{Discussion}

Temperature, which can be manipulated easily in the cell culture process, and possibly also in the clinical treatment, may be one of the key microenvironmental parameters regulating the chondrogenic phenotype and ECM formation. We investigated the effects of three different culture temperatures $\left(32^{\circ} \mathrm{C}, 37^{\circ} \mathrm{C}\right.$, and $\left.41^{\circ} \mathrm{C}\right)$ on the ability of dedifferentiated mature human chondrocytes to redifferentiate and form ECM in vitro. To the best of our knowledge, this is the first report on the effect in vivo intra-articular temperature on human chondrocyte metabolism in vitro. Our results demonstrated that the wet weight measured up to day 21 showed time-dependent increases at $32^{\circ} \mathrm{C}$ and $37^{\circ} \mathrm{C}$, suggesting ECM accumulation (Fig. 1b). However, on the other hand, the wet weight at $41^{\circ} \mathrm{C}$ did not change over time. 
Moreover, the ECM-related genes (COL2A1, COL1A1, ACAN, and COMP) at $41^{\circ} \mathrm{C}$ were

209 significantly down-regulated compared to at $32^{\circ} \mathrm{C}$ and $37^{\circ} \mathrm{C}$ (Fig. 2a-d). These results from 210 the mRNA expression analysis are consistent with those of the safranin-O staining and the

211 IHC staining of type II and I collagens (Fig. 3), as well as with the results of the GAG

212 quantification (Fig. 6a), which all indicated that ECM formation was dramatically inhibited at

$21341^{\circ} \mathrm{C}$. To elucidate this phenomenon further, we observed the generated pellets at $41^{\circ} \mathrm{C}$ using

214 SEM to clarify the ultra-microstructure of the collagen, and found that the collagen fiber

215 content in these pellets was very low (Fig. 5). In addition, the results of the DNA

216 quantification suggested that there were significant decreases in the cell number within the

217 pellets at $41^{\circ} \mathrm{C}$, by day 14 of culture (Fig. 6b).

218 Peltonen et al. ${ }^{23}$ reported that collagen cannot fold into a triple-helix conformation at a temperature of approximately $40^{\circ} \mathrm{C}$. Therefore, the reasons for the inhibition of $\mathrm{ECM}$ formation at $41^{\circ} \mathrm{C}$ may be explained by a combination of cell loss, inhibition of ECM-related mRNA expression, and perhaps also by collagen misfolding. Thus, while intermittent heat stimuli may have a positive effect on ECM formation ${ }^{13,14}$, prolonged exposure to heat stimuli may have the opposite effect, and we should hence consider heat stimuli as a thermal dose combining both temperature and duration. ${ }^{24}$

Interestingly, in this study, the wet weight showed time-dependent increases at $32^{\circ} \mathrm{C}$ and $37^{\circ} \mathrm{C}$ (Fig. 1b), indicating that a cooler environment $\left(32^{\circ} \mathrm{C}\right)$ can resemble ECM produced at $37^{\circ} \mathrm{C}$, although the wet weight of samples in the $37^{\circ} \mathrm{C}$ was significantly higher than samples in the $32^{\circ} \mathrm{C}$ group on days 14 and 21 . The wet weight of $\mathrm{AC}$ is known to be mainly composed of water (60-85\%), type II collagen (15-22\%), and proteoglycan (4-7\%). ${ }^{25}$ As proteoglycan traps water, the most important factor affecting the wet weight is thought to be the proteoglycan content. Herein, we observed a strong correlation between the proteoglycan 
content and the wet weight (Supplementary Fig. 2); and therefore, the wet weight was thought to be heavier at $37^{\circ} \mathrm{C}$ due to the higher proteoglycan content (Figs. 3 and 6).

Compared to $32^{\circ} \mathrm{C}$, from the aspect of the differentiation state, the culture temperature of $37^{\circ} \mathrm{C}$ appeared to enhance redifferentiation of the pellet, which comprised dedifferentiated chondrocytes. Dedifferentiated chondrocytes exhibit increasing fibro-cartilage marker type I collagen and decreasing hyaline-cartilage marker type II collagen. ${ }^{4,5}$ In this study, the COL2A1 mRNA expression (Fig. 2a) and type II collagen protein synthesis (Fig. 4) were higher at $37^{\circ} \mathrm{C}$ compared to at $32^{\circ} \mathrm{C}$. As for the proteoglycan synthesis (Figs. 3 and $6 \mathrm{c}$ ), the culture temperature of $37^{\circ} \mathrm{C}$ was also associated with a higher synthesis rate compared to $32^{\circ} \mathrm{C}$ in the late phase (day 21). Therefore, in our experimental condition, the culture temperature of $37^{\circ} \mathrm{C}$ was able to induce redifferentiation at a higher rate than $32^{\circ} \mathrm{C}$, likely by promoting type II collagen synthesis in the early phase and proteoglycan synthesis in the late phase. Taken together, these results suggest that the cells implanted in a patient through ACI are likely to be affected by the intra-articular temperature, and that their growth would be promoted by regulating the temperature at approximately $37^{\circ} \mathrm{C}$.

The findings from the picrosirius red staining observed under a polarizing microscope showed that integrated collagen fibers were observed in the deep region from day 14 at $32^{\circ} \mathrm{C}$ (Fig. 3 [white arrow]), whereas it was mainly observed in the superficial region at $37^{\circ} \mathrm{C}$. These collagen architectural differences according to the culture temperature are consistent with the findings of previous studies that used immature porcine chondrocytes. ${ }^{16}$ Furthermore, upon SEM observation, the collagen fibers in the transition and deep regions also seemed to be denser at $32^{\circ} \mathrm{C}$ than at $37^{\circ} \mathrm{C}$ (Fig. 5). In addition, we noted that the compressive response of the pellets was altered by the culture temperature (Supplementary Fig. 3). Although the detailed mechanism of this phenomenon remains unclear, these findings suggest that thermal 
environment may affect the function of an articular cartilage. To verify this possibility, further investigations are needed.

Our study has a few limitations. First, the detailed signaling cascade responsible for inducing the differences in chondrocyte metabolism according to the different culture temperatures remains unclear. Second, we investigated only three typical culture temperature conditions. The intra-knee joint temperature in active osteoarthritis and rheumatoid arthritis has been reported to be $34-36^{\circ} \mathrm{C},{ }^{11}$ and the temperature is altered by the patients' physical activity level. ${ }^{26}$ Thus, further investigations are needed to apply multilevel temperature conditions in order to gain an understanding of the precise effects of thermal environment on chondrocytes. Third, we only analyzed cells obtained from two individuals. Therefore, in order to generalize our findings, larger studies are warranted in the future.

In conclusion, the culture temperature of $37^{\circ} \mathrm{C}$, which mimics the inner body temperature, was found to promote redifferentiation and ECM formation better than $32^{\circ} \mathrm{C}$, which mimics the in vivo intra-articular temperature, whereas that of $41^{\circ} \mathrm{C}$ drastically inhibited $\mathrm{ECM}$ formation. Therefore, modulation of thermal environment might represent an advantageous means to regulate the phenotype and biosynthetic activity of chondrocytes. In addition, in vitro experiments should consider the culture temperature, since this markedly influences the chondrocyte metabolism and phenotype.

\section{Acknowledgments}

The authors wish to thank Keiko Okamoto-Furuta and Haruyasu Koda (Kyoto University, Kyoto) for their skilled technical assistance and advice. This study was supported in part by a Grant-in-Aid for JSPS Research Fellows (no. 25-3611), a JSPS KAKENHI Grant-in-Aid for 
279 Scientific Research (A) (no. 25242055), and a JSPS KAKENHI Grant-in-Aid for Challenging 280 Exploratory Research (no. 25560258). The authors declare no competing interests. 
1. Mollon B, Kandel R, Chahal J, et al. 2013. The clinical status of cartilage tissue regeneration in humans.

Osteoarthritis Cartilage 21: 1824-1833.

2. Kim HK, Moran ME, Salter RB. 1991. The potential for regeneration of articular cartilage in defects created by chondral shaving and subchondral abrasion. An experimental investigation in rabbits. J Bone Joint Surg Am 73: 1301-1315.

3. Brittberg M, Lindahl A, Nilsson A, et al. 1994. Treatment of deep cartilage defects in the knee with autologous chondrocyte transplantation. N Engl J Med 331: 889-895.

4. von der Mark K, Gauss V, von der Mark H, et al. 1977. Relationship between cell shape and type of collagen synthesised as chondrocytes lose their cartilage phenotype in culture. Nature 267: 531-532. enter the cell cycle and co-express collagen type I in monolayer culture. J Orthop Res 32: 1503-1511.

6. Freyria AM, Mallein-Gerin F. 2012. Chondrocytes or adult stem cells for cartilage repair: the indisputable role of growth factors. Injury 43: 259-265.

7. Mouw JK, Case ND, Guldberg RE, et al. 2005. Variations in matrix composition and GAG fine structure among scaffolds for cartilage tissue engineering. Osteoarthritis Cartilage 13: 828-836.

8. Domm C, Schunke M, Christesen K, et al. 2002. Redifferentiation of dedifferentiated bovine articular chondrocytes in alginate culture under low oxygen tension. Osteoarthritis Cartilage 10: 13-22.

9. Elder SH, Sanders SW, McCulley WR, et al. 2006. Chondrocyte response to cyclic hydrostatic pressure in alginate versus pellet culture. J Orthop Res 24: 740-747. articular cartilage metabolism. Arthroscopy 27: 526-531. 

continuous cryotherapy on the intra-articular temperature of the knee. Arthroscopy 21: 552-556. applicator on cartilage matrix gene and HSP70 expression in the rabbit knee joint. J Orthop Res 26: 34-41. 14. Chen J, Li C, Wang S. 2014. Periodic heat shock accelerated the chondrogenic differentiation of human mesenchymal stem cells in pellet culture. PLoS One 9: e91561.

15. Ito A, Aoyama T, Yamaguchi S, et al. 2012. Low-intensity pulsed ultrasound inhibits messenger RNA expression of matrix metalloproteinase-13 induced by interleukin-1 $\beta$ in chondrocytes in an intensity-dependent manner. Ultrasound Med Biol 38: 1726-1733.

16. Ito A, Aoyama T, lijima $\mathrm{H}$, et al. 2014. Optimum temperature for extracellular matrix production by articular chondrocytes. Int J Hyperthermia 30: 96-101.

17. Dewey WC, Hopwood LE, Sapareto SA, et al. 1977. Cellular responses to combinations of hyperthermia and radiation. Radiology 123: 463-474.

18. Wheatley DN, Kerr C, Gregory DW. 1989. Heat-induced damage to HeLa-S3 cells: correlation of viability, permeability, osmosensitivity, phase-contrast light-, scanning electron- and transmission electron-microscopical findings. Int J Hyperthermia 5: 145-162.

19. Ito A, Aoyama T, Tajino J, et al. 2014. Evaluation of reference genes for human chondrocytes cultured in several different thermal environments. Int J Hyperthermia 30: 210-216.

20. Changoor A, Tran-Khanh N, Méthot S, et al. 2011. A polarized light microscopy method for accurate and reliable grading of collagen organization in cartilage repair. Osteoarthritis Cartilage 19: 126-135. 21. Iijima H, Aoyama T, Ito A, et al. 2014. Immature articular cartilage and subchondral bone covered by menisci are potentially susceptive to mechanical load. BMC Musculoskelet Disord 15: 101. glycosaminoglycans by use of dimethylmethylene blue. Biochim Biophys Acta 883: 173-177. 
329 23. Peltonen L, Palotie A, Hayashi T, et al. 1980. Thermal stability of type I and type III procollagens from 330 normal human fibroblasts and from a patient with osteogenesis imperfecta. Proc Natl Acad Sci USA 77: $331 \quad 162-166$.

332 24. Dewhirst MW, Viglianti BL, Lora-Michiels M, et al. 2003. Basic principles of thermal dosimetry and 333 thermal thresholds for tissue damage from hyperthermia. Int J Hyperthermia 19: 267-294.

334 25. Mow VC, Ratcliffe A, Poole AR. 1992. Cartilage and diarthrodial joints as paradigms for hierarchical 335 materials and structures. Biomaterials 13: 67-97.

336 26. Becher C, Springer J, Feil S, et al. 2008. Intra-articular temperatures of the knee in sports - an in-vivo 337 study of jogging and alpine skiing. BMC Musculoskelet Disord 9: 46. 
340 Figure 1: Macroscopic observations and wet weight.

(a) Representative images of the generated pellets. Scale bar $=1 \mathrm{~mm}$. (b) Wet weight

Values are presented as means $\pm 95 \%$ confidence intervals $(n=9$ pellets/group; $* P<0.05$, $32^{\circ} \mathrm{C}$ vs. $37^{\circ} \mathrm{C} ; * * P<0.01,32^{\circ} \mathrm{C}$ vs. $37^{\circ} \mathrm{C} ; \ddagger P<0.01,32^{\circ} \mathrm{C}$ vs. $41^{\circ} \mathrm{C} ; \S \S P<0.01,37^{\circ} \mathrm{C}$ vs. $\left.41^{\circ} \mathrm{C}\right)$.

Figure 2: Gene expression analysis.

Relative mRNA expressions of (a) collagen type II A1 (COL2A1), (b) collagen type I A1 (COL1A1), (c) aggrecan $(A C A N)$, and (d) cartilage oligomeric matrix protein $(C O M P)$ are shown. These genes were up-regulated from days 3 to 7 at $32^{\circ} \mathrm{C}$ and $37^{\circ} \mathrm{C}$, but not at $41^{\circ} \mathrm{C}$. COL2A1 and $C O M P$ at $37^{\circ} \mathrm{C}$ were significantly higher than at $32^{\circ} \mathrm{C}$ on days 3 and 7 . There were no significant differences in the COL1Al and ACAN gene expressions between $32^{\circ} \mathrm{C}$ and $37^{\circ} \mathrm{C}$. The gene expressions at $41^{\circ} \mathrm{C}$ were all significantly down-regulated. Values are presented as means $\pm 95 \%$ confidence intervals $\left(n=3\right.$ pellets/group; $* P<0.05,32^{\circ} \mathrm{C}$ vs. $37^{\circ} \mathrm{C} ; * * P<0.01,32^{\circ} \mathrm{C}$ vs. $37^{\circ} \mathrm{C} ; \dagger P<0.05,32^{\circ} \mathrm{C}$ vs. $41^{\circ} \mathrm{C} ; \ddagger P<0.01,32^{\circ} \mathrm{C}$ vs. $41^{\circ} \mathrm{C} ; \S P<$ $0.05,37^{\circ} \mathrm{C}$ vs. $41^{\circ} \mathrm{C} ; \S \S P<0.01,37^{\circ} \mathrm{C}$ vs. $\left.41^{\circ} \mathrm{C}\right)$.

Figure 3: Histological and immunohistochemical analyses.

Representative images of the histological and immunohistochemical findings are shown. and $37^{\circ} \mathrm{C}$, but not at $41^{\circ} \mathrm{C}$. Picrosirius red staining demonstrated integrated collagen fibers in 
362

363

364

365

the deep region of the pellet at $32^{\circ} \mathrm{C}$ on days 14 and 21 (white arrow). Scale bar $=500 \mu \mathrm{m}$; magnification, $\times 100$.

Figure 4: Semi-quantitative evaluation of type II collagen immunohistochemical staining.

(a) The mean type II collagen intensity per pixel and (b) the mean percentage of the type II collagen positive area were calculated on day 21 . Both values were higher at $37^{\circ} \mathrm{C}$ than at $32^{\circ} \mathrm{C}$. Values are presented as means $\pm 95 \%$ confidence intervals $(n=8$ pellets/group; $* * P<$ $0.01)$.

Figure 5: Scanning electron microscope observations.

Representative images of the surface and cut surface of the generated pellets on day 21 are shown. The surfaces at $32^{\circ} \mathrm{C}$ and $37^{\circ} \mathrm{C}$, but not at $41^{\circ} \mathrm{C}$, appeared to be even and smooth. In the cut surface, dense and layered collagen fibers parallel to the surface were observed in the superficial region at $32^{\circ} \mathrm{C}$ and at $37^{\circ} \mathrm{C}$, but not at $41^{\circ} \mathrm{C}$. The collagen fibers in the transition and deep regions at $32^{\circ} \mathrm{C}$ seemed to be denser than those at $37^{\circ} \mathrm{C}$. Scale bar $=10$ $\mu \mathrm{m}$; magnification, $\times 2000$.

Figure 6: Glycosaminoglycan (GAG) and deoxyribonucleic acid (DNA) content.

(a) The GAG content per pellet at $37^{\circ} \mathrm{C}$ tended to be higher than that at $32^{\circ} \mathrm{C}$, and that at $41^{\circ} \mathrm{C}$ was significantly lower than at the other two culture temperatures. (b) The DNA content per pellet at $41^{\circ} \mathrm{C}$ was significantly lower than at the other temperature environments. (c) The GAG content normalized by the DNA content (GAG/DNA) was significantly higher at $37^{\circ} \mathrm{C}$ than at $32^{\circ} \mathrm{C}$ on day 21 . Values are presented as means $\pm 95 \%$ confidence intervals $(n=6$ pellets/group; $* * P<0.01)$. 
a

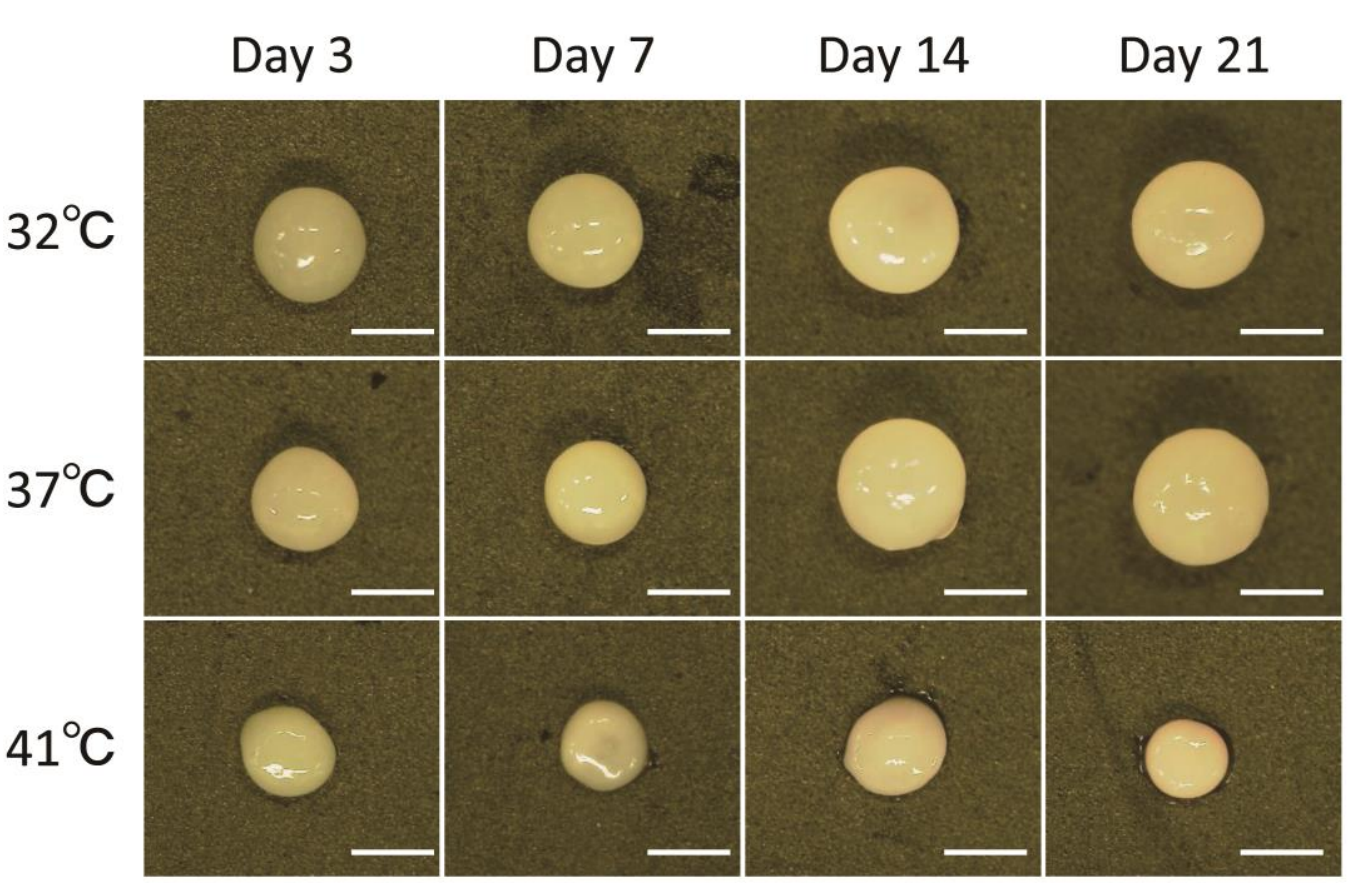

b

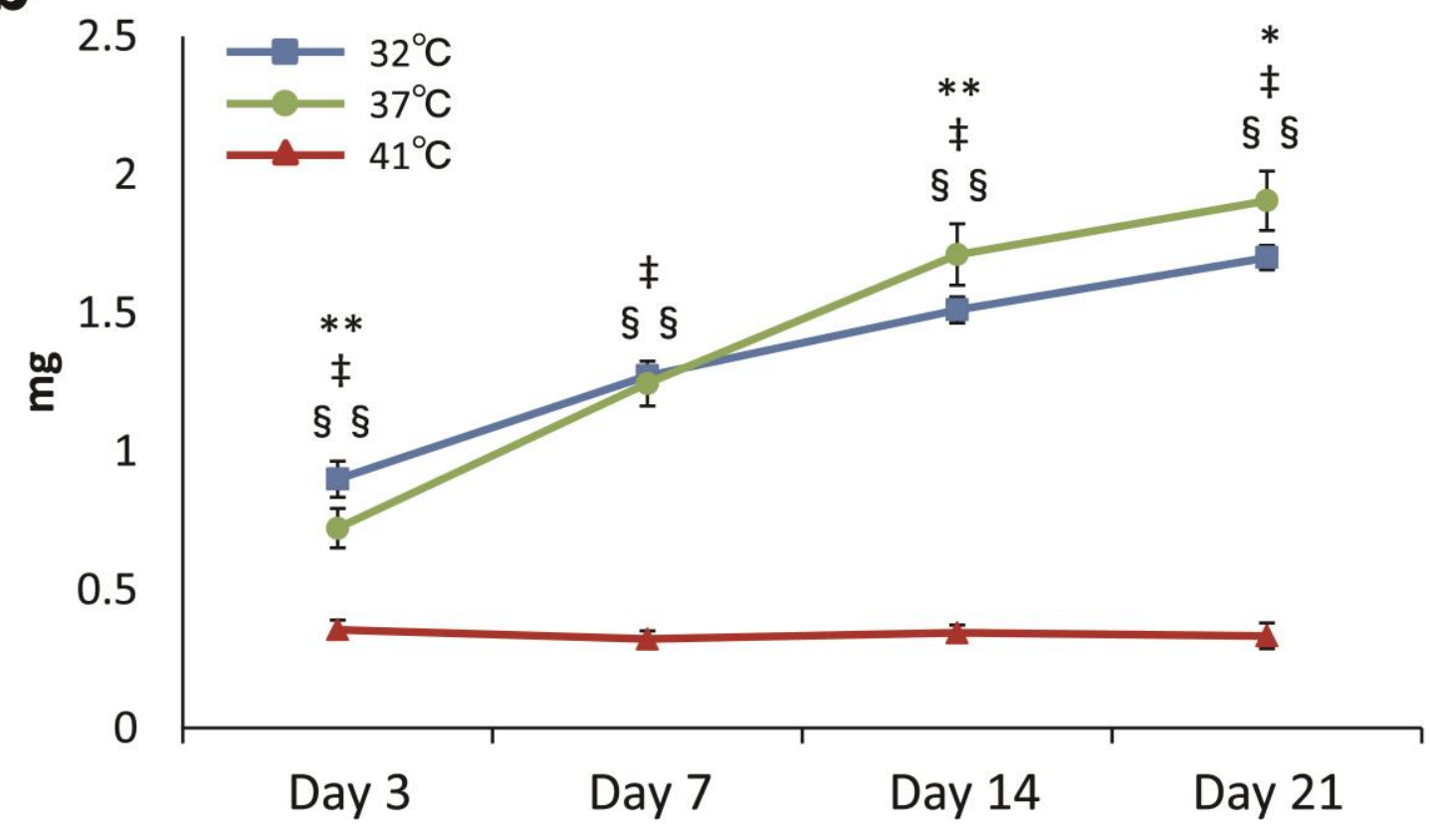



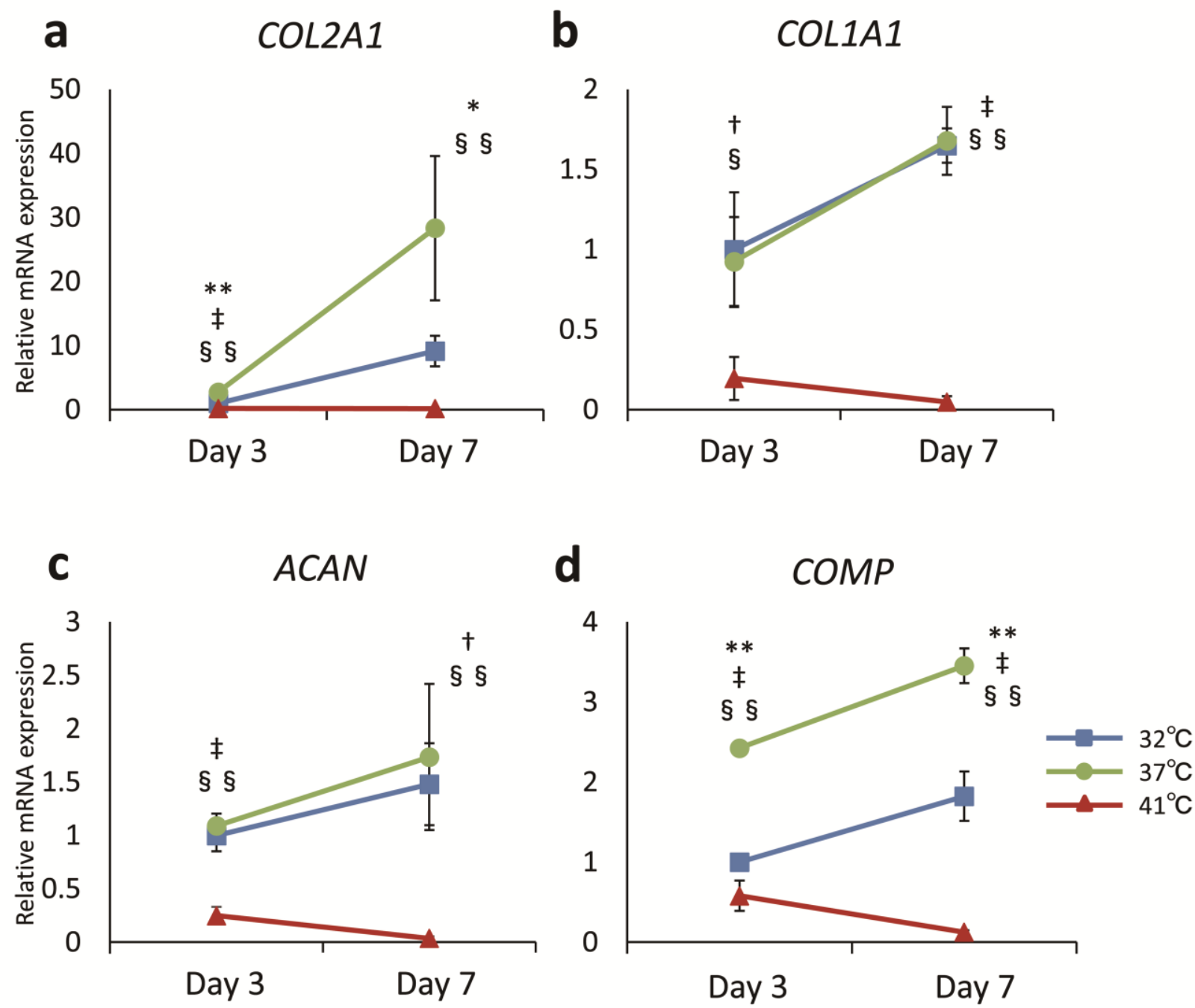

Figure 2

391 


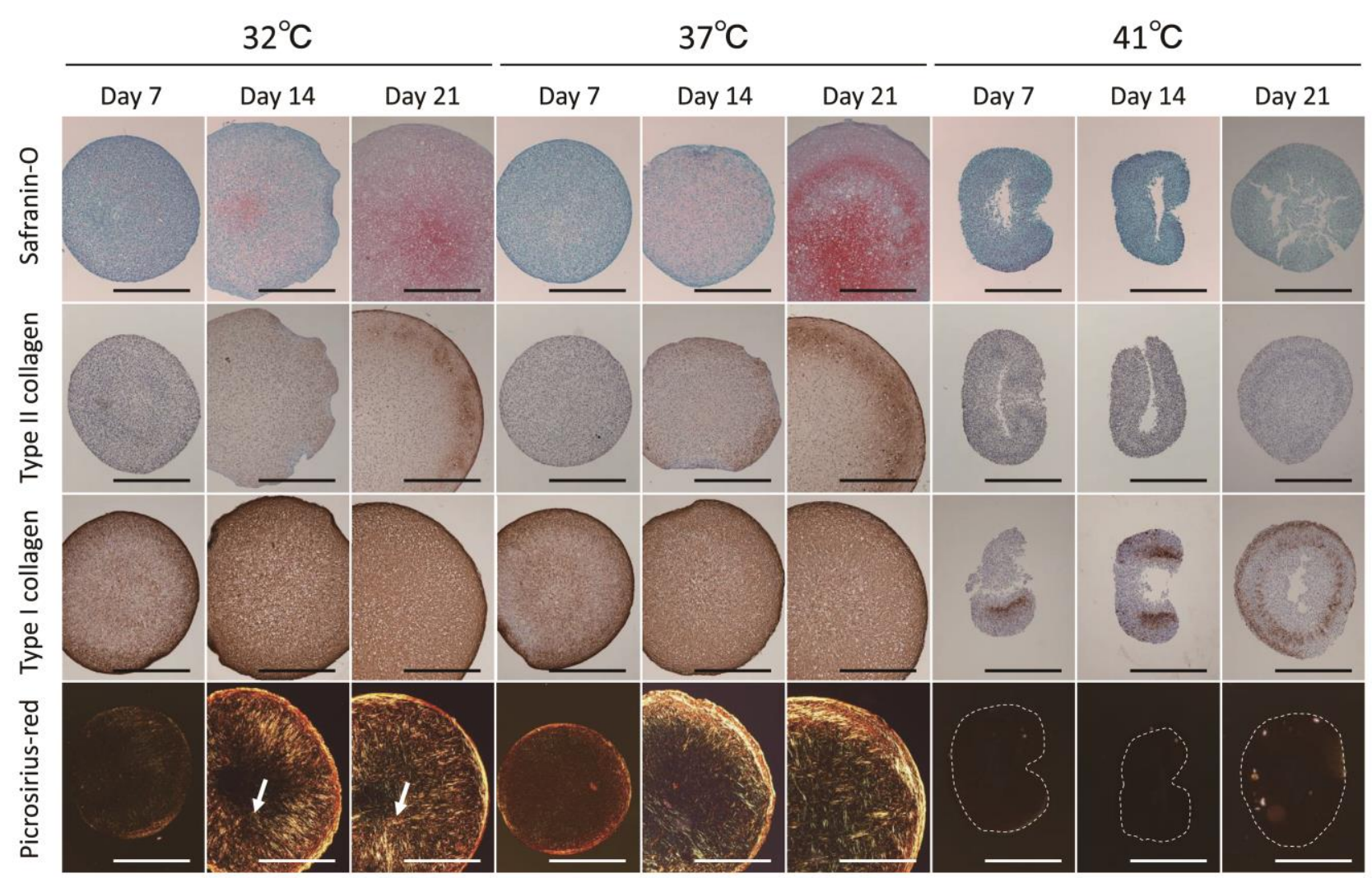

Figure 3 


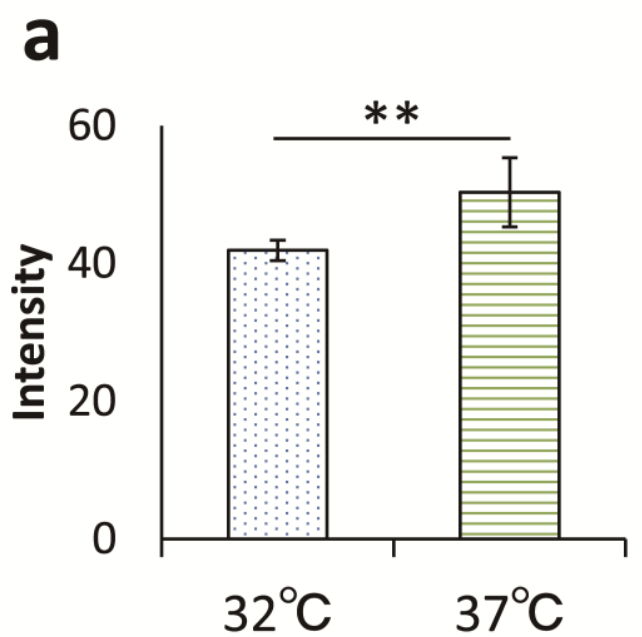

395

b

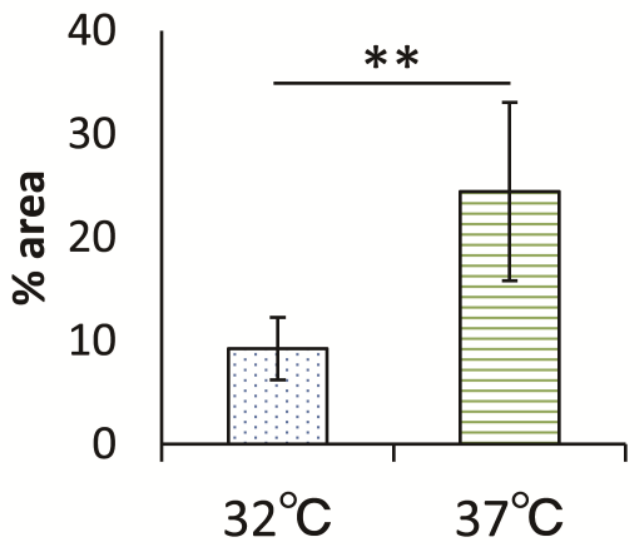

396

Figure 4

397 

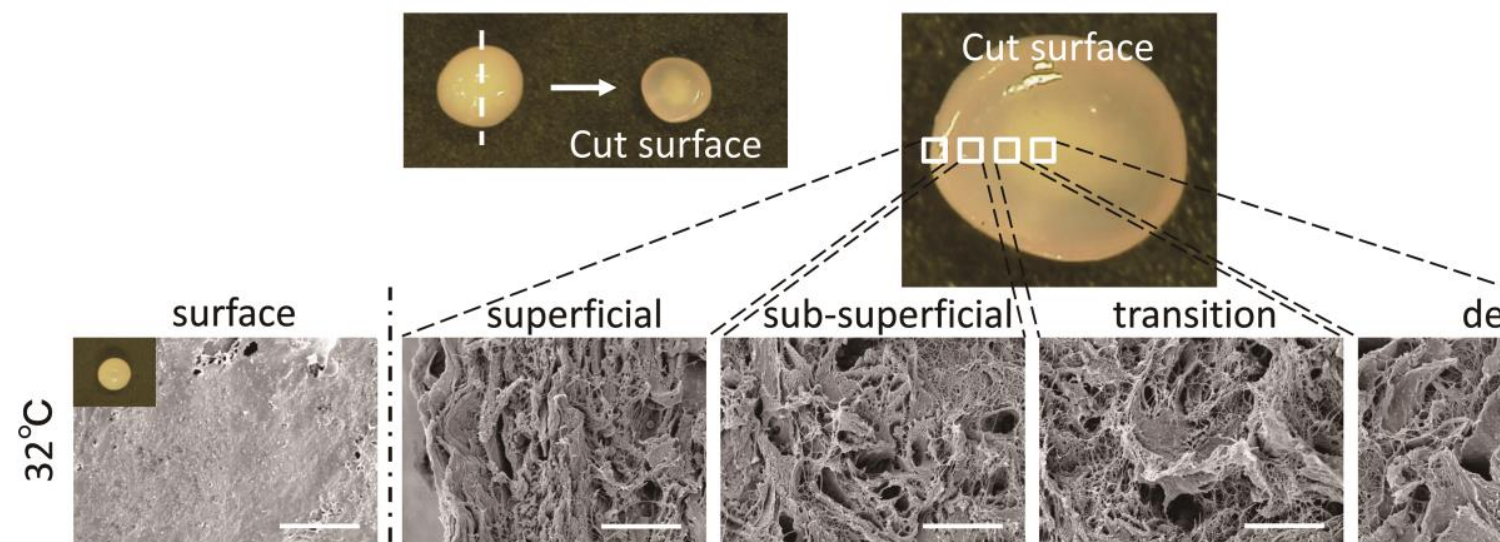

śsub-superficiali transition deè
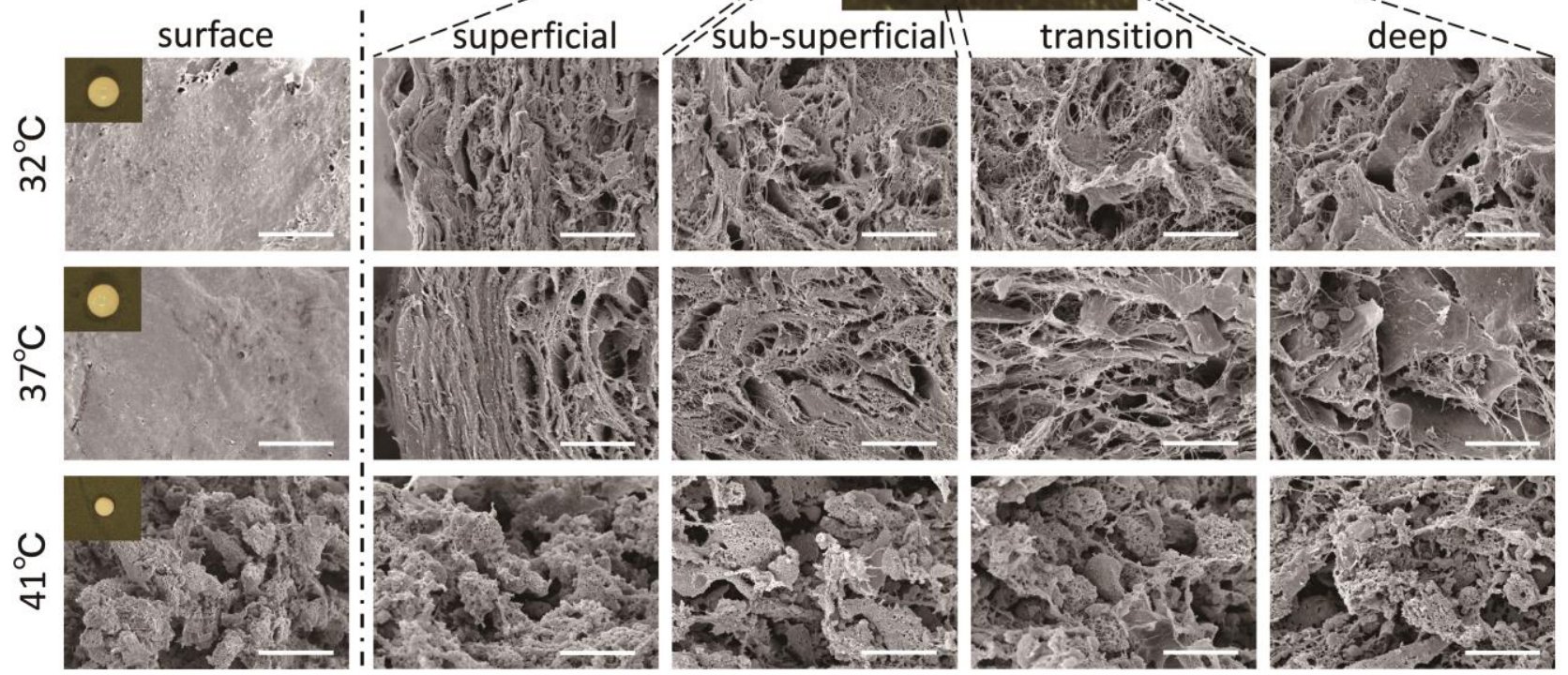

Figure 5 
401

402

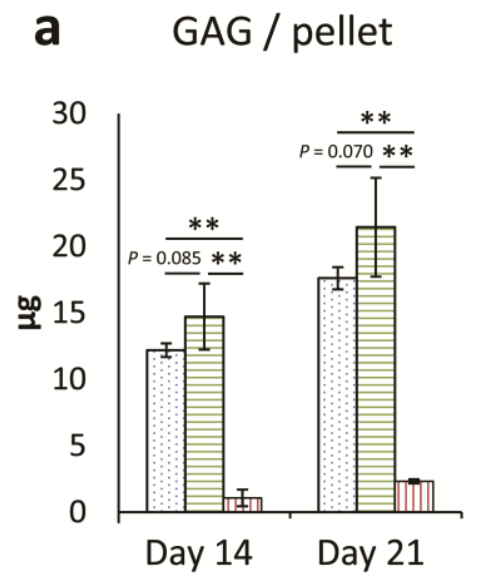

b DNA / pellet

c GAG / DNA

403
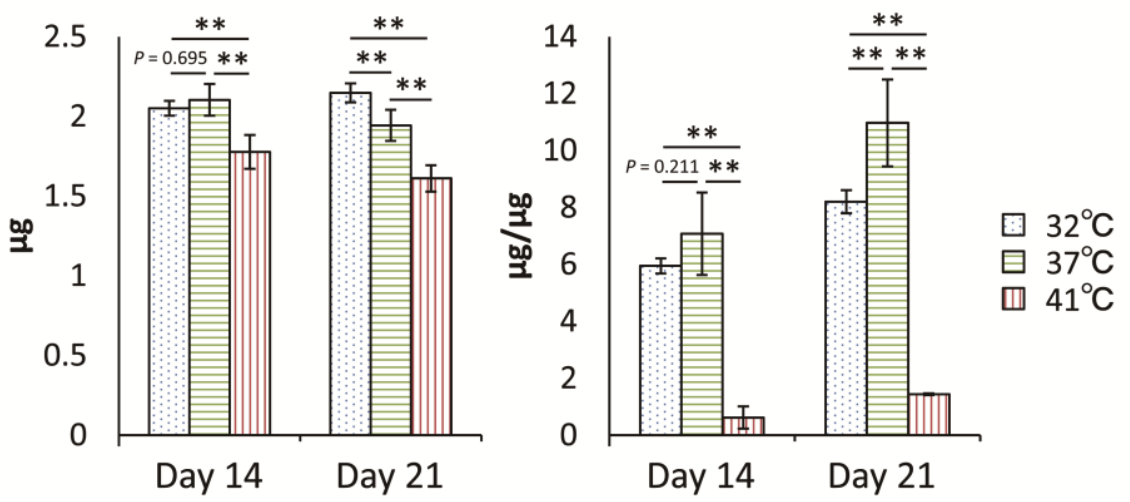

404

Figure 6 
407

Supplementary Table 1. Primer sequences for qRT-PCR

\begin{tabular}{lllc}
\hline & \multicolumn{1}{c}{ Sense $\left(5^{\prime}-3^{\prime}\right)$} & \multicolumn{1}{c}{ Antisense $\left(5^{\prime}-3^{\prime}\right)$} & $\begin{array}{c}\text { Length } \\
(\mathrm{bp})\end{array}$ \\
\hline COL2A1 & GCTATGGAGATGACAACCTGGCTC & CACTTACCGGTGTGTTTCGTGCAG & 256 \\
COL1A1 & CAGAACGGCCTCAGGTACCA & CAGATCACGTCATCGCACAAC & 101 \\
ACAN & GAATTTCCTGGCGTGAGAAC & GGGGATGTTGCGTAAAAGAC & 107 \\
COMP & AACAGTGCCCAGGAGGAC & TTGTCTACCACCTTGTCTGC & 191 \\
RPL13a & AAGTACCAGGCAGTGACAG & CCTGTTTCCGTAGCCTCATG & 100 \\
$Y W H A Z$ & TGCTTGCATCCCACAGACTA & AGGCAGACAATGACAGACCA & 126 \\
\hline
\end{tabular}

409 
a

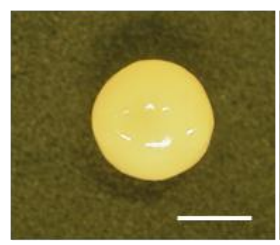

$32^{\circ} \mathrm{C}$

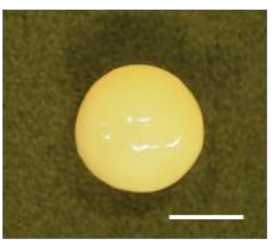

$37^{\circ} \mathrm{C}$

b

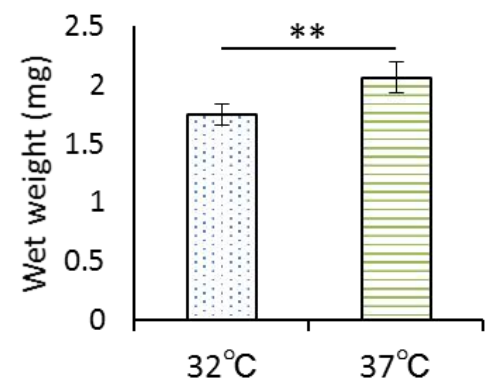

C $\operatorname{COL} 2 A 1$

COL1A1
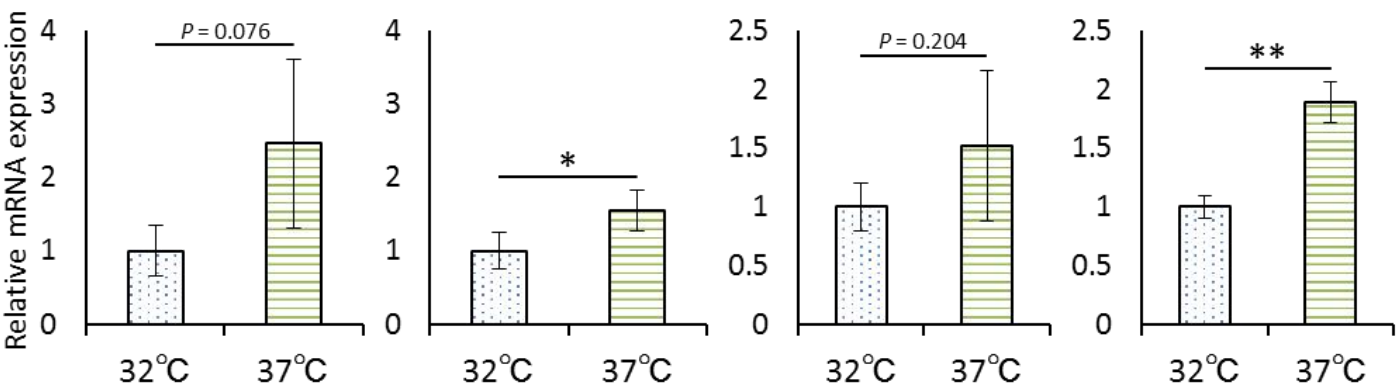

d

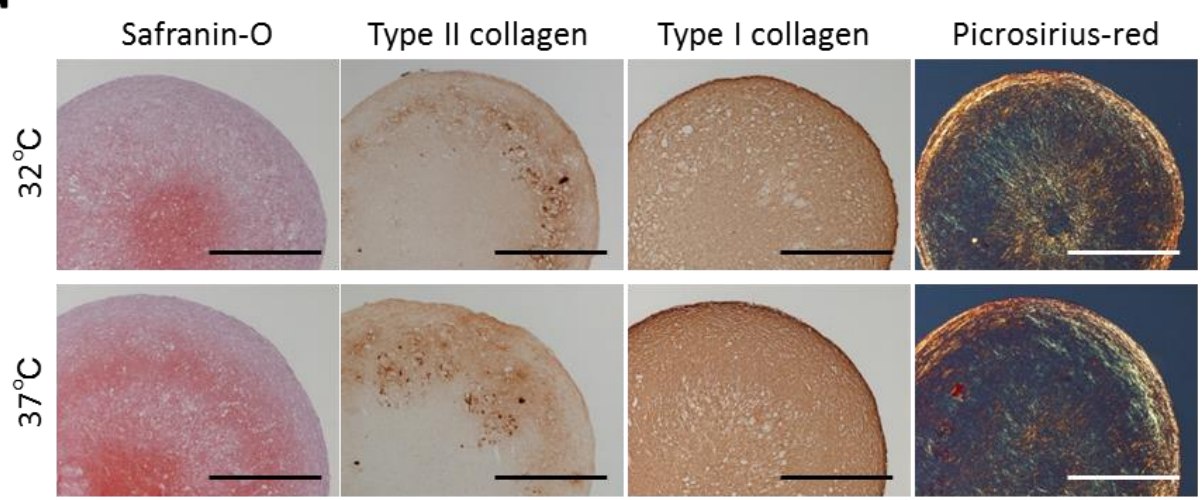

e
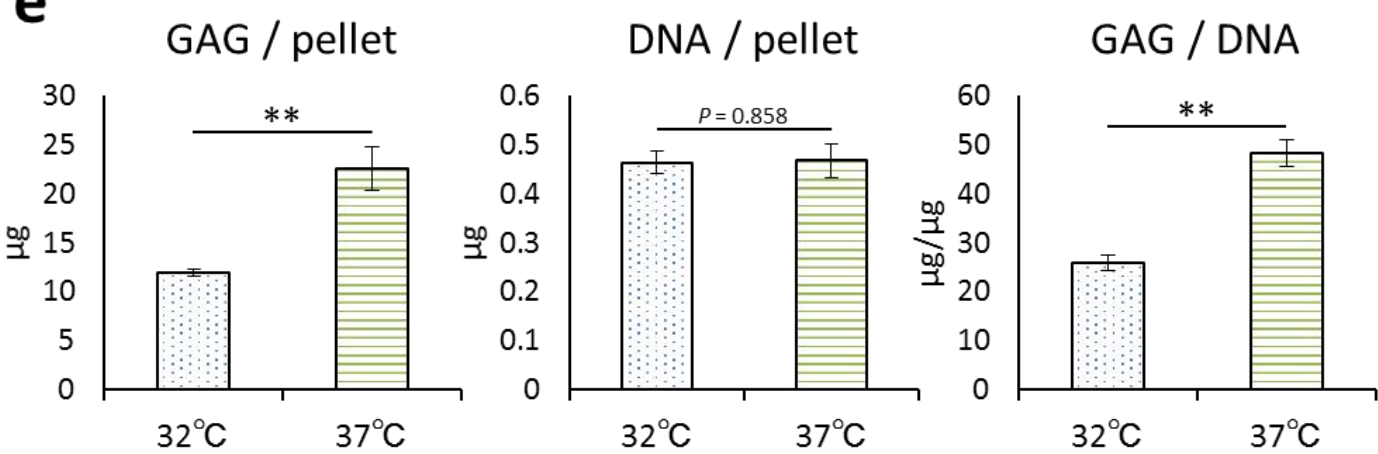

410

411 Supplementary Figure 1: Results from donor B. 
The pellets from donor B cultured at $32^{\circ} \mathrm{C}$ and $37^{\circ} \mathrm{C}$ were harvested at 3 and 21 days to

413 confirm the reproducibility of the findings from donor A. (a) Representative images of the 414 generated pellets at 21 days. Scale bar $=1 \mathrm{~mm}$. (b) Wet weight of the pellets at 21 days. The 415 wet weight was heavier at $37^{\circ} \mathrm{C}$ than at $32^{\circ} \mathrm{C}$. Values are presented as means $\pm 95 \%$ 416 confidence intervals $(n=6$ pellets/group; $* * P<0.01)$. (c) Relative mRNA expressions of 417 COL2A1, COL1A1, ACAN, and COMP at 3 days. These genes showed similar trends to those 418 observed for donor A (Fig. 2), except for COL1A1. COL1A1 was slightly, but significantly higher at $37^{\circ} \mathrm{C}$ than at $32^{\circ} \mathrm{C}$. Values are presented as means $\pm 95 \%$ confidence intervals $(n=3$ pellets/group; $* P<0.05$, $* * P<0.01$ ). (d) Representative images of the histological and 421 immunohistochemical findings at 21 days. Similar results as for donor A (Fig. 3) were obtained. Scale bar $=500 \mu \mathrm{m}$; magnification, $\times 100$. (e) GAG and DNA content per pellet and the GAG/DNA ratio at 21 days. Similar results as for donor A (Fig. 6) were obtained. Values

424 are presented as means $\pm 95 \%$ confidence intervals $(n=6$ pellets/group; $* * P<0.01)$.

Abbreviations: mRNA, messenger ribonucleic acid; COL2A1, collagen type II A1; COL1A1, collagen type I A1; ACAN, aggrecan; COMP, cartilage oligomeric matrix protein; GAG, glycosaminoglycan; DNA, deoxyribonucleic acid. 


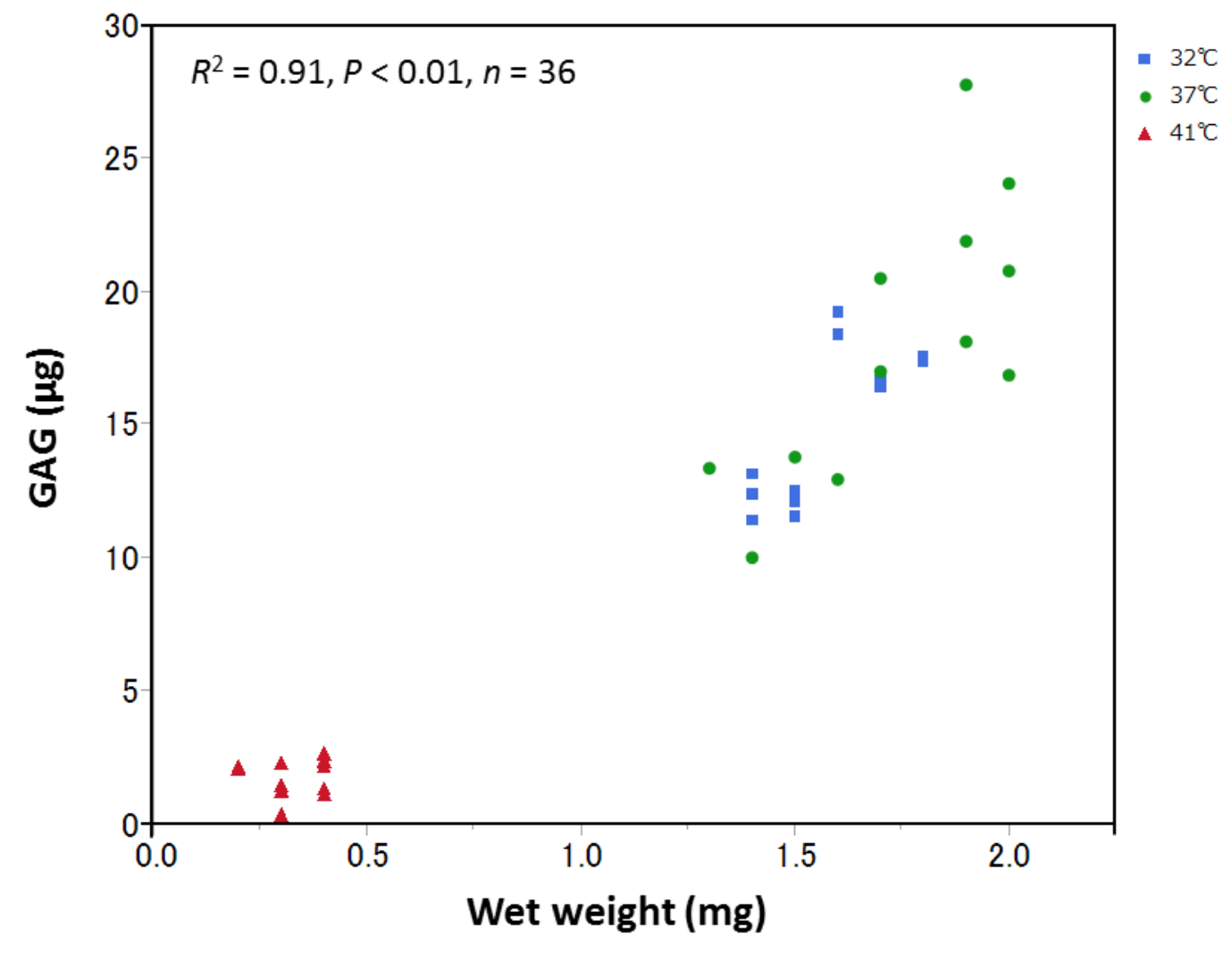

431 Supplementary Figure 2: The correlation between the glycosaminoglycan (GAG) content 432 and the wet weight.

433 The correlation between the GAG content and the wet weight examined using the

434 Pearson's correlation coefficient has a strong correlation $\left(R^{2}=0.91, P<0.01, n=36\right.$; blue 435 square, $32^{\circ} \mathrm{C}$; green circle, $37^{\circ} \mathrm{C}$; red triangle, $41^{\circ} \mathrm{C}$ ). 


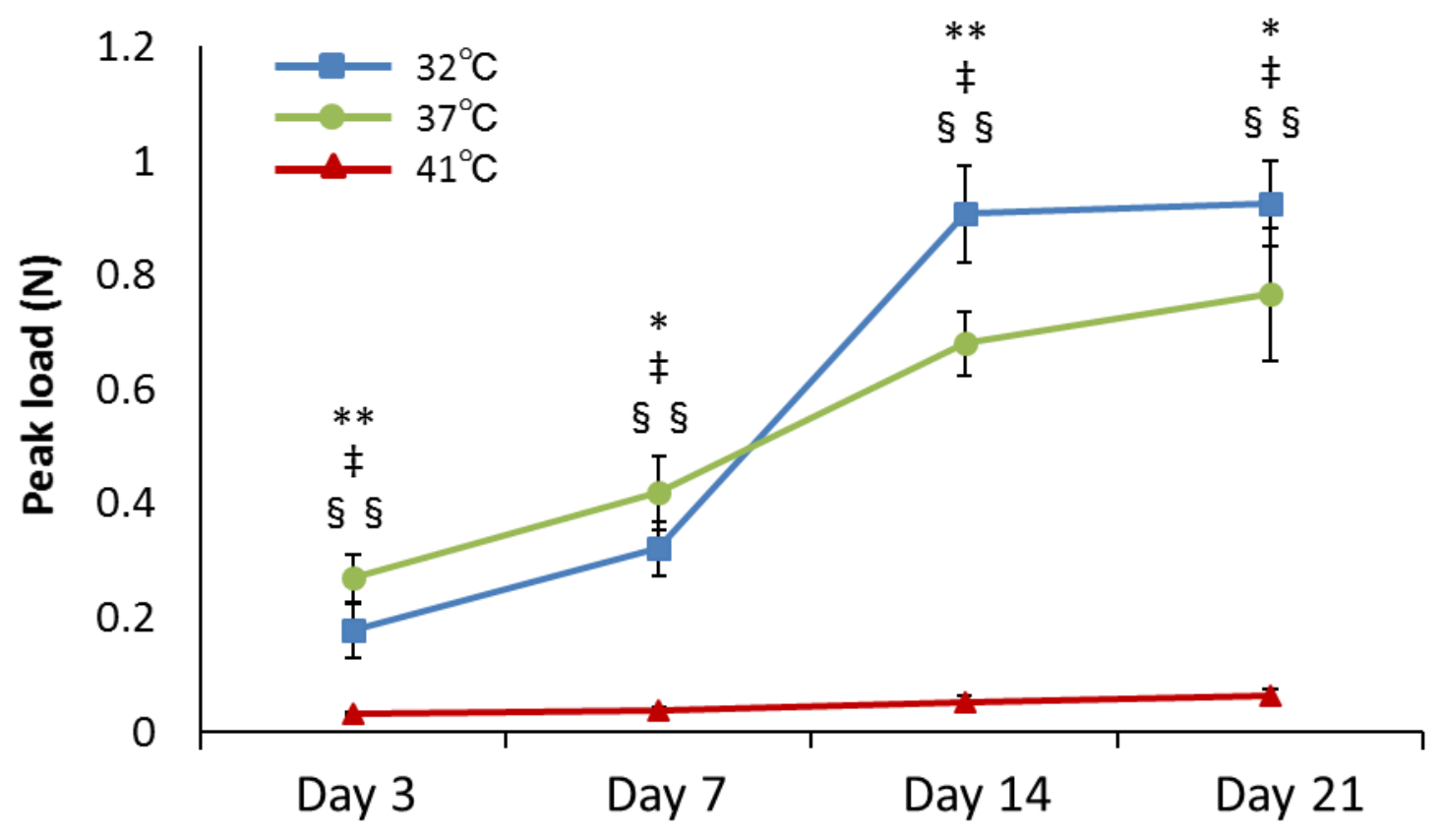

438 Supplementary Figure 3: Biomechanical analysis.

To analyze biomechanical property of the generated pellets cultured at $32^{\circ} \mathrm{C}, 37^{\circ} \mathrm{C}$, and

$41^{\circ} \mathrm{C}$, an unconfined compression test was performed using a mechanical testing instrument

with the use of a 3-mm diameter indenter (Autograph AG-X; Shimadzu, Kyoto, Japan). Each pellet on days $3,7,14$, and 21 was compressed uniaxially in a testing chamber filled with PBS at room temperature. A pre-load of $0.01 \mathrm{~N}$ was applied and allowed to equilibrate for 60 sec. Then the loading was applied at a strain rate of $0.005 \mathrm{~mm} / \mathrm{s}$ (up to a $50 \%$ strain), and peak load (N) was obtained.

The peak load was higher at $37^{\circ} \mathrm{C}$ until day 7 . However, after day 14 , it was inverted, and 447 the pellets generated at $32^{\circ} \mathrm{C}$ showed a significantly higher peak load. The peak load at $41^{\circ} \mathrm{C}$ 448 was significantly lower than others at all days. Values are represented as means $\pm 95 \%$ confidence intervals $\left(n=6\right.$ pellets/group; ${ }^{*} P<0.05,32^{\circ} \mathrm{C}$ vs. $37^{\circ} \mathrm{C} ; * * P<0.01,32^{\circ} \mathrm{C}$ vs. $37^{\circ} \mathrm{C} ; \ddagger P<0.01,32^{\circ} \mathrm{C}$ vs. $41^{\circ} \mathrm{C} ; \S \S P<0.01,37^{\circ} \mathrm{C}$ vs. $\left.41^{\circ} \mathrm{C}\right)$. 